\title{
A High Sensitivity Sensor Based CRLH and CSRR For Liquid mixture Identification
}

\author{
Mohamed Lashab ${ }^{1}$, Sekkache Hocine ${ }^{2}$, Mounir Belattar ${ }^{2}$, Jamal Kosha ${ }^{3}$, W.F.A. Mshwat ${ }^{3}$ \\ Douablia Linda $^{2}$, Aziza Zermane ${ }^{4}$, Zebiri Chemss Eddine ${ }^{5}$, R.A. Abd-Alhameed ${ }^{3}$ \\ \{lashabmoh@yahoo.fr ${ }^{1}$, hocine.sek@gmail.com², mounir.belattar@yahoo.com ${ }^{3}$ \} \\ ${ }^{1}$ University Larbi Ben M'hidi, Oum El-Bouaghi, Algeria. \\ ${ }^{2}$ University 20 Aout 55, Skikda, Algeria. \\ ${ }^{3}$ Faculty of Engineering and Informatics, Bradford, UK. \\ ${ }^{4}$ Université Mustapha Benboulaid Batna-2, ${ }^{5}$ University Ferhat Abbas, Setif-1, Algeria.
}

\begin{abstract}
A very high sensitivity sensor based composite right left hand (CRLH) resonator and CSRR (complementary split-ring resonator) for liquid mixture application is investigated. The geometrical size of the sensor are $16 \mathrm{~mm} \times 10 \mathrm{~mm}$, the substrate is based on FR4 epoxy, very short testing surface $5 \mathrm{~mm} \times 8 \mathrm{~mm}$, the combination of the two types of resonators provides high sensitivity and miniaturization. The frequency range is covering $1.5 \mathrm{GHz}$ to $2.5 \mathrm{GHz}$. The sensor is modelled and computed using the commercial software HFSS (high-frequency structural simulator). The liquids under test are ethanol and methanol. The achieved results are compared to existing work in the literature, these are very promising.
\end{abstract}

Keywords: Sensor, CSSR, CRLH, HFSS, Liquid mixture, Ethanol, Methanol.

\section{Introduction}

In the last decade the technology of composite right left hand (CRLH) resonator is being used to improve antenna performances, this technology first introduced by Sanada et al. I [1], it is characterized by a combination of left hand $(\mathrm{LH})$ and right hand $(\mathrm{RH})$. The sensor or the antenna based on this technology presents a resonant frequency that is independent of the dimension of the structure, known as well by Zero Order Resonators (ZOR), also considered as metamaterial behavior as presented in [2], later improved by Hakjune et al. [3-4]. The CSRRs (complementary split-ring resonators) was proposed by Thomas et al. in 2004 [5] and can have a circular shape or square shape with multiple split-ring resonators.

The first work published in the literature concerning liquid characterization was presented by Bao \& al. [4], where he recorded the permittivity and the tangent loss of the ethanol and methanol by volume fraction of water. The work considered open-ended of the coaxial probe method, with the use of Debye function over a very wide frequency range, (from $0.5 \mathrm{GHz}$ to 10 $\mathrm{GHz}$ ), similar work on the complex dielectric characterization of the liquid mixture was presented in [5].

Recently more interesting research work was carried out by others, such as Saeed [6], Ebrahimi [7], Benkhaoua [8] and [9-16] these works are dealing with a liquid mixture with a different design, looking out for better or high sensitivity. 
The basic principle operation of microwave sensors is to measure the variation of the resonance frequency when sitting closely or attached the material under test. At the resonance frequency, an electric field appears to be dominated for liquid identification and biomedical sensing.

The present paper presents a design of novel sensor with two ports, this is loaded with CRLH resonator, in the ground plane, it is added a CSRR (Complementary Split Ring Resonator). This work is aimed to increase the sensor sensitivity, and also to enable the miniaturization effect.

\section{Sensor design And theoretical study}

\subsection{Theoretical aspect}

The main elements of the new sensor model are the CRLH-unit cell on the front side and the CSRR on the ground plane side. The sensor can be simulated then optimized engine process of HFSS software. The equivalent electric circuits of the proposed sensor are given below in Figure 1.
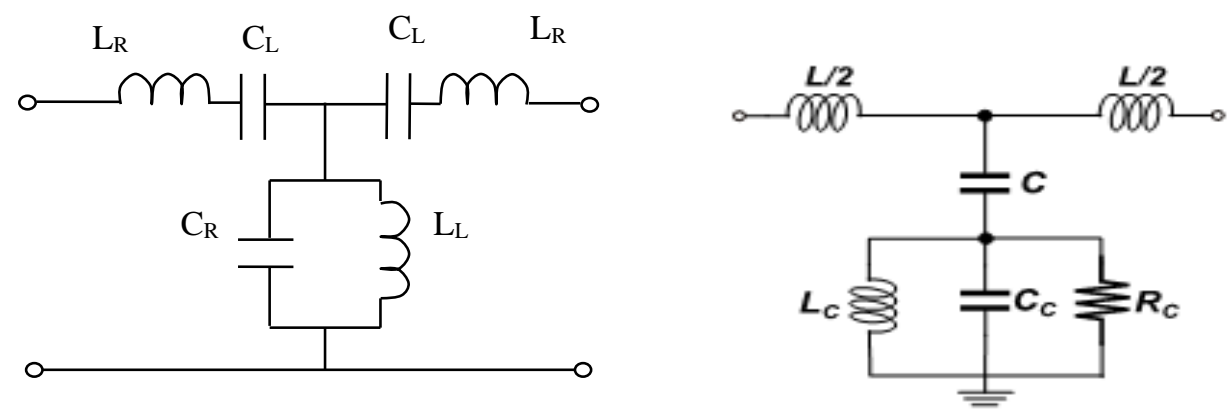

Fig.1 equivalent circuit of the proposed sensor, a) top view, b)bottom view

In the CRLH unit cell, the impedance $\mathrm{Z}$ provides a series of resonators based on $\left(\mathrm{L}_{\mathrm{R}}, \mathrm{C}_{\mathrm{L}}\right)$, whereas $\mathrm{Y}$ admittance provides a parallel resonator based on $\left(\mathrm{L}_{\mathrm{L}}, \mathrm{C}_{\mathrm{R}}\right)[1]$.

\subsection{Geometrical dimension of the sensor}

The sensor structure is presented in Figure. 2. It is mounted on FR4 substrate that is characterized by relative permittivity $\varepsilon_{r}=4.4$ and dielectric loss tangent $\delta=0.02$, the thickness of the substrate of $1.6 \mathrm{~mm}$. The sensor is composed of CRLH and CSRR circuits with two ports, the sensor presents a coplanar port feeder, grounded at the bottom side.

The input impedance of the two ports are set to $50 \Omega$, this will enable suitable impedance matching, the geometrical dimension of the sensor is given in Table 1. 


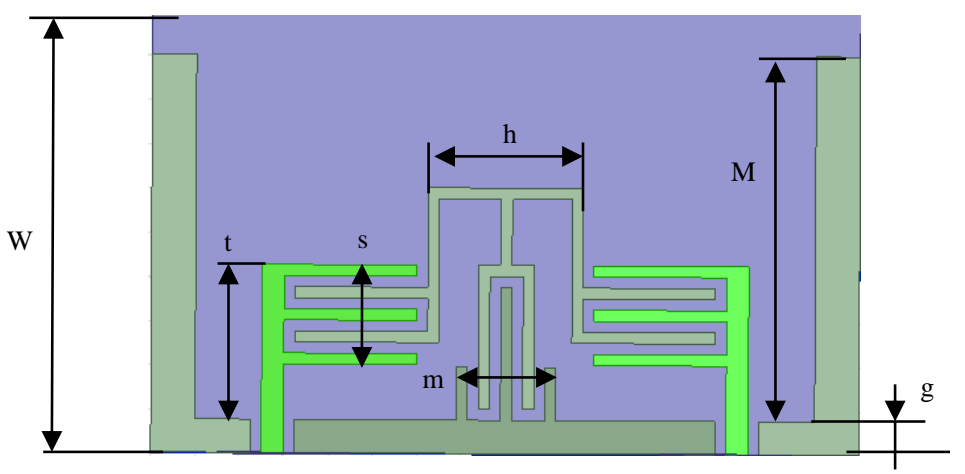

(a)

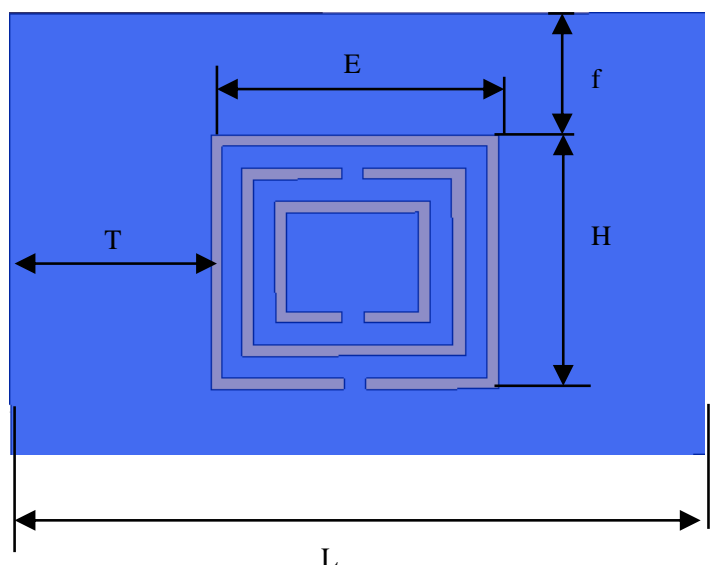

(b)

Fig. 2, Proposed sensor, a) top view, b)bottom view

Table 1. List of the proposed sensor dimensions in (mm)

\begin{tabular}{|c|c|c|c|c|c|}
\hline $\mathrm{L}$ & $\mathrm{W}$ & $\mathrm{H}$ & $\mathrm{E}$ & $\mathrm{M}$ & $\mathrm{T}$ \\
\hline 16 & 10 & 6.5 & 6.5 & 8.25 & 3.5 \\
\hline $\mathrm{h}$ & $\mathrm{s}$ & $\mathrm{t}$ & $\mathrm{m}$ & $\mathrm{f}$ & $\mathrm{g}$ \\
\hline 3.25 & 3.5 & 4.5 & 2.5 & 2.0 & 1.0 \\
\hline
\end{tabular}

\section{Results and discussion}

The transmission coefficient of the sensor without liquid mixture (Air), the bottom ground is first with PEC ground and second with CSRR, the results are presented in Figure 3. The transmission coefficients of the considered liquids present four resonant frequencies between $0.54 \mathrm{GHz}$ and 3 $\mathrm{GHz}$, the core of these are $2.55 \mathrm{GHz}$ and $2.67 \mathrm{GHz}$, respectively for without CSRR and with 
CSRR. The sensor is then loaded with two liquid mixtures, Ethanol and Methanol, the transmissions coefficients are giving resonant frequency respectively $1.9 \mathrm{GHZ}$ and $1.3 \mathrm{GHz}$. It seems that the ground with CSRR enables the frequency range of the sensor which is in favor of the sensitivity.

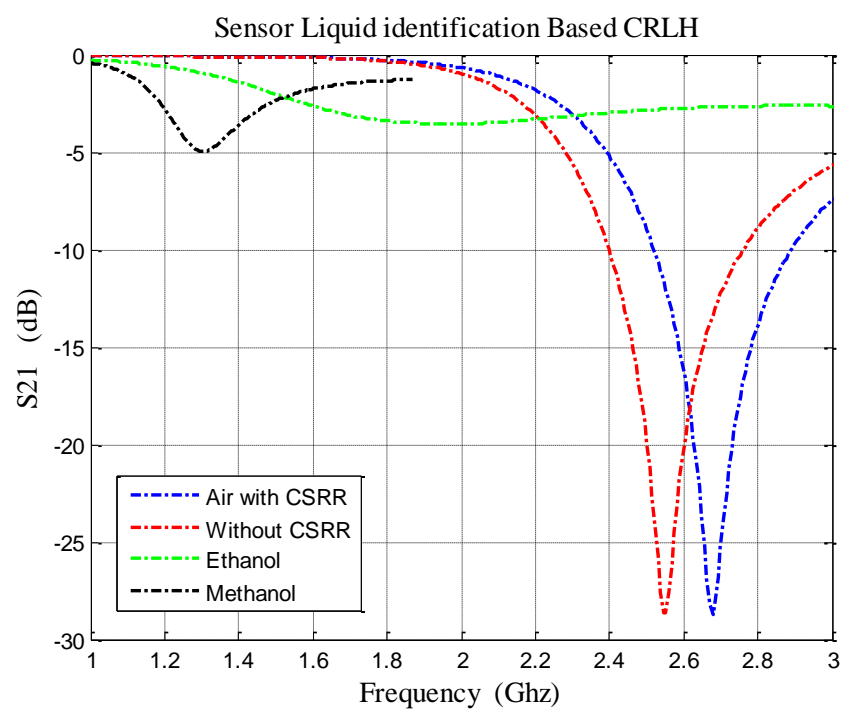

Fig.3 Transmission coefficient with and without CSRR

Sensor Liquid identification of Ethanol, without CSRR

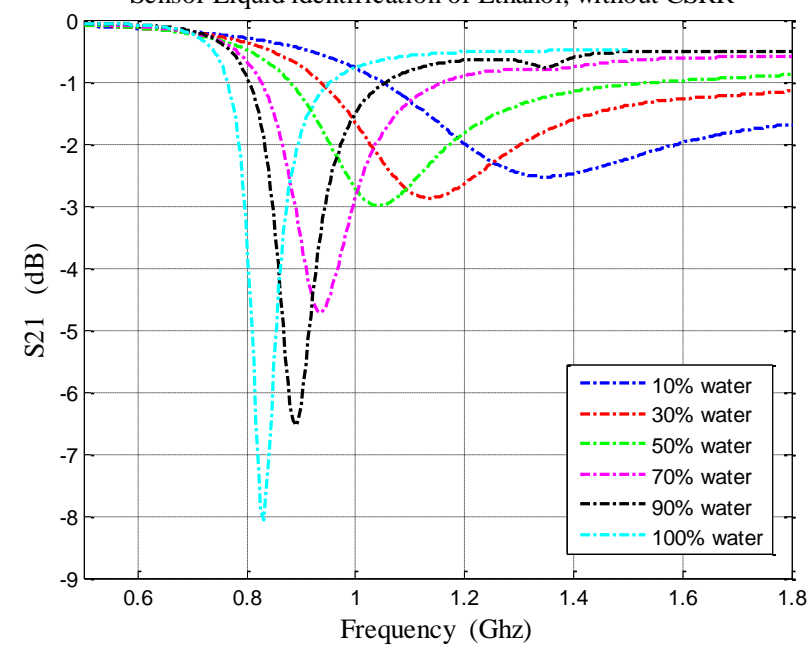

Fig.4 Transmission coefficient of the ethanol without CSRR 
The $S_{21}$ of the sensor without CSRR using a different fraction of water-ethanol is presented in Figure 4 . The frequency range of the sensor is from $0.83 \mathrm{GHz}$ to $1.34 \mathrm{GHz}$, a difference of $0.51 \mathrm{GHz}$. The transmission coefficient S21 of the sensor loaded with CSRR is given in Figure 5, the frequency range is from $0.795 \mathrm{GHz}$ to $1.365 \mathrm{GHz}$, a difference of $0.57 \mathrm{GHz}$. An increase of $11.7 \%$ of the bandwidth of the sensor when using CSRR ground.

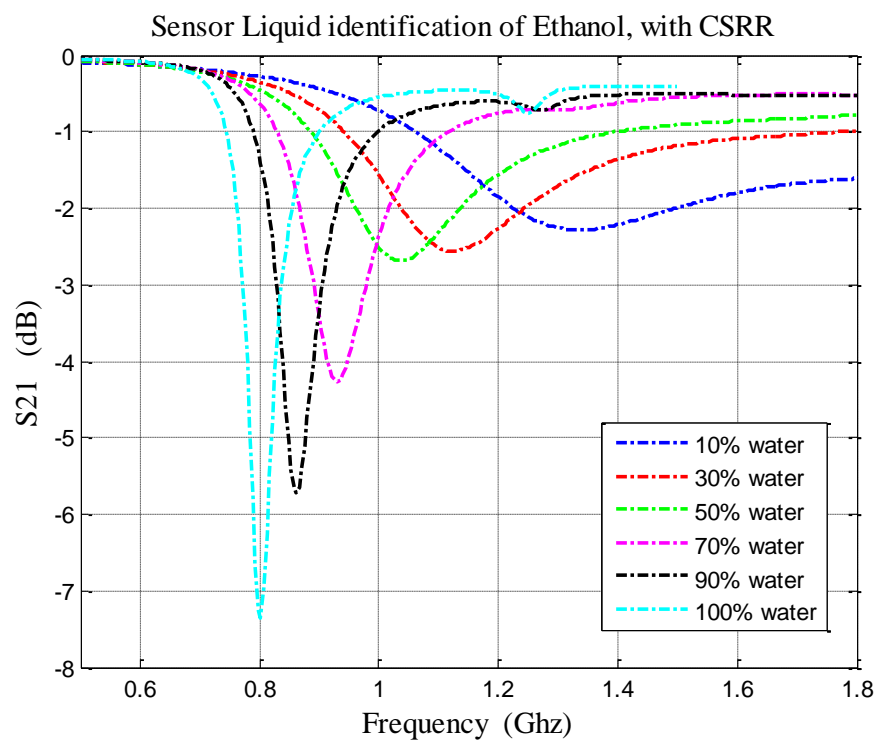

Fig.5 Transmission coefficient of the ethanol with CSRR

A comparison of the volume fraction of the ethanol with and without CSRR is presented in Figure 6, there is a remarkable difference in higher volume fraction and almost none in the lower volume fraction. The liquid under test is presented in Figure 7, the liquid is supposed to be placed on the top of the sensor in a rectangular shape, the input port and the output port are in the same side as shown in the figure.

The measured permittivity $\varepsilon^{\prime}$ according to Debye function model is expressed with respect to the real part of the permittivity regarding the properties of the liquid given by [7], the given relation in (1), depends on a lower frequency and high frequency of the measured range of frequency.

$$
\varepsilon^{\prime}=\varepsilon_{\infty}+\frac{\varepsilon_{S}-\varepsilon_{\infty}}{1+\omega^{2} \tau^{2}}
$$

We define, $\varepsilon s$ the permittivity of the lower frequency and $\varepsilon \infty$ is the permittivity of the higher frequency, $\tau$ is the relaxation time and $\omega$ is the operating frequency. 
Since the measured values of the transmission coefficient are almost stable in the considered range of frequency, the dispersion coefficient is not taken into account. The sensitivity of the sensor can be expressed by the following relation [8].

$$
S=\frac{f_{o}-f_{1}}{f_{o} d \varepsilon_{r}}
$$

Where $f_{o}$ is the lower frequency of the sensor $(0.795 \mathrm{GHz})$ and $f_{1}$ is an upper frequency of sensor ( 1.365$)$, and $d \varepsilon_{r}$ is the variation in the relative permittivity from volume fraction of $10 \%$ to $100 \%$ which is considered of $(25-80=55)$. The computed sensitivity has achieved the maximum value given by:

$$
(1.365-0.795) /(1.365 \times 55)=0.75 \%
$$

A sensitivity of $0.75 \%$, which is a very high compared to the literature in [6],[7],[8], [11] and [16], given respctively as $0.11 \%, 0.27 \%, 0.54 \%, 0.26 \%$ and $0.14 \%$.

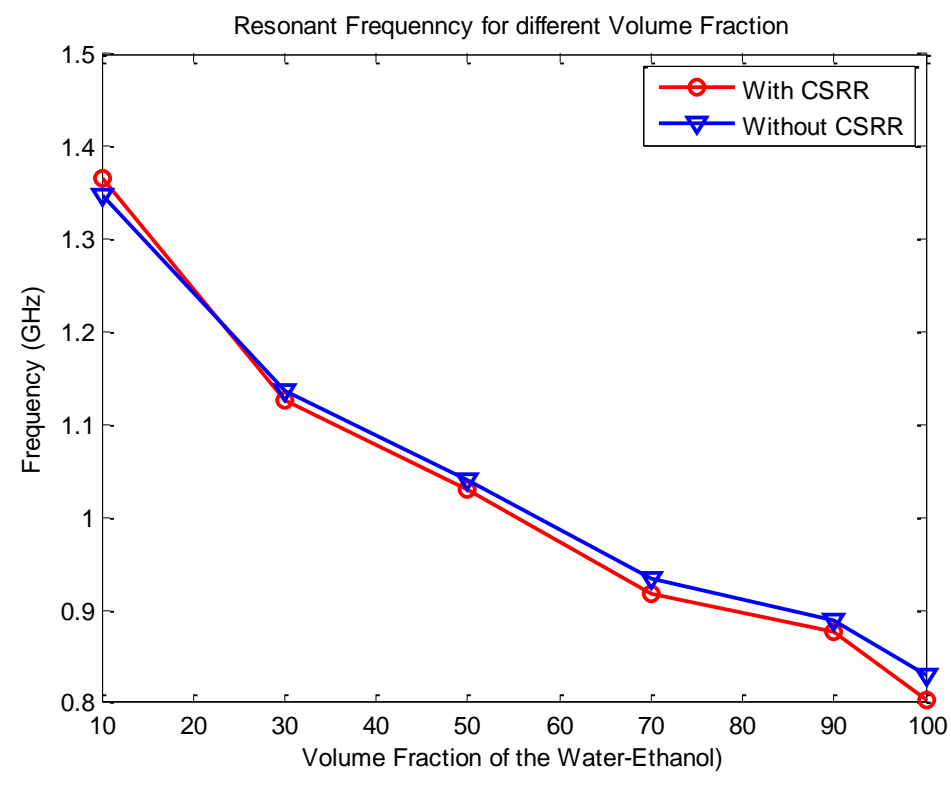

Fig.6 Resonant Frequency versus Fraction Volume of Water of the ethanol With and Without CSRR 


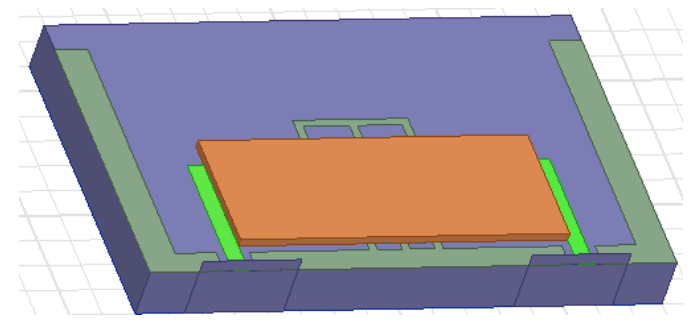

\section{Conclusion}

Fig. 7, Sensor loaded with a liquid mixture

The work presented in this paper is dealing with liquid mixture identification, basically ethanol and methanol. The sensor design is a miniaturized structure based on CRLH resonator built from the left hand and right-hand metamaterial, in addition a CSRR is inserted in the ground plane in order to improve the sensitivity. The simulation model was carried our over two types of a liquid mixture that are tested with volume fraction of the methanol and ethanol.

The simulation has resulted in very high sensitivity comparatively with previous work done in the literature, also the geometrical dimension of the sensor is miniaturized, as well as the surface under test where the liquid should be placed. The CSRR ground plane enables to extension the bandwidth of the sensor hence increasing the sensitivity of the sensor.

\section{References}

[1] A. Sanada, C. Caloz and T. Itoh, "Zeroth Order in Composite right/left-handed transmission line resonators", in Proc. Asia-pasific Microwave Conf. Seoul Kouria Nov 2003.

[2] Long Li, Zhen Jia, Feifei Huo, and Weiqiang Han "A Novel Compact Multiband Antenna Employing Dual-Band CRLH-TL for Smart Mobile Phone Application," IEEE Antennas and Wireless Propagation Letters, Vol. 12, 2013.

[3] Hakjune Lee, Duk-Jae Woo, and Sangwook Nam, "Compact and Bandwidth-Enhanced Asymmetric Coplanar Waveguide (ACPW) Antenna Using CRLH-TL and Modified Ground Plane," IEEE Antennas and Wireless Propagation Letters, Vol. 15, 2016.

[4] Jian-Zhong Bao, Mays L. Swicord, Christopher C. Davis, "Microwave Dielectric Characterization of Binary Mixtures of Water, methanol, and ethanol," J. Chem. Phys. 104 (12), 22 March 1996.

[5] Thomas Meissner and Frank J. Wentz "The Complex Dielectric Constant of Pure and Sea Water From Microwave Satellite Observations," IEEE Transaction on Geoscience And Remote Sensing, Vol. 42, No. 9, Sep. 2004.

[6] Kashif Saeed, Roger D. Pollard and Ian C. Hunter, "Substrate Integrated Waveguide Cavity Resonators for Complex Permittivity Characterization of Materials," IEEE Transaction on Microwave Theory and Techniques, Vol. 56, No. 10, Oct 2008.

[7] Amir Ebrahimi, Withawat Withayachumnankul, Said Al-Sarawi, Derek Abbott, "High-Sensitivity Metamaterial-Inspired Sensor for Microfluidic Dielectric Characterization," IEEE Sensors Journal, Vol. 14, No. 5, 2014.

[8] Larbi Benkhaoua, Mohamed Taoufik Benhabiles, Mohamed Lahdi Riabi \& smail Mouissat, "Miniaturized Quasi-Lumped Resonator for Dielectric Characterization of Liquid Mixtures," IEEE Journal \& Magazine, Vol. 16, Iss. 06, 2016.

[9] Ali M. Albishi, Omar M. Ramahi, “Microwaves-Based High Sensitivity Sensors for Crack Detection in Metallic Materials,” IEEE Tansaction on Microwave Theory and Techniques, Vol. 65, Iss. 5, 2017. 
[10] Euclides Lourenço Chuma, Yuzo Iano, Glauco Fontgalland, and Leonardo Lorenzo Bravo Roger, "Microwave Sensor for Liquid Dielectric Characterization based on Metamaterial Complementary Split Ring Resonator,” IEEE Sensors Journal, Vol. 18, Issu. 24, 2018.

[11] Chretiennot, T.; Dubuc, D.; Grenier, K., "A Microwave and Microfluidic Planar Resonator for Efficient and Accurate Complex Permittivity Characterization of Aqueous Solutions," Microwave Theory and Techniques, IEEE Transactions on , vol.61, no.2, pp.972,978, Feb. 2013.

[12] Paris Vélez, Lijuan Su, Katia Grenier, Javier Mata-Contreras, David Dubuc, and Ferran Martín, «Microwave Microfluidic Sensor Based on a Microstrip Splitter/Combiner Configuration and Split Ring Resonators (SRRs) for Dielectric Characterization of Liquids, » IEEE Sensors Journal, Vol. 17, No. 20, 2017

[13] Nonchanutt Chudpooti, Evans Silavwe, Prayoot Akkaraekthalin, Ian D. Robertson, "Nano-Fluidic Millimeter-Wave Lab-on-a-Waveguide Sensor for Liquid-Mixture Characterization," IEEE Sensors Journal, Vol. 18, No. 1, 2018.

[14] Mohamed Lashab, Jamal Kosha, Fathi M. Abdussalam, Mounir Belattar, Linda Djouablia, Chems Eddine Zebiri", Fatiha Benabdelaziz, R.A.Abd-Alhameed, "Design and Optimization of Electromagnetic Sensor Based On CRLH Resonator,” LAPC 2018, Loughborough, UK.

[15] Paris Vélez, Katia Grenier, Javier Mata-Contreras, David Dubuc, and Ferran Martín, "HighlySensitive Microwave Sensors based on Open Complementary Split Ring Resonators (OCSRRs) for Dielectric Characterization and Solute Concentration Measurement in Liquids," IEEE Access, Vol. 6, 2018.

[16] Gennarelli, G.; Romeo, S.; Scarfi, M.R.; Soldovieri, F., "A Microwave Resonant Sensor for Concentration Measurements of Liquid Solutions," Sensors Journal, IEEE, vol.13, no.5, pp.1857,1864, May 2013 